\title{
Acquired Neurogenic Bladder
}

National Cancer Institute

\section{Source}

National Cancer Institute. Acquired Neurogenic Bladder. NCI Thesaurus. Code C123204.

Neurogenic bladder, the cause of which is not present at birth. 